\title{
A Case of Hedonic Perception of Foreigners towards Chinese Culture-Specific Odors from Scent Marketing Perspective
}

\author{
Anna Vinnikova \\ School of Management \\ University of Science and Technology of China \\ Hefei, China
}

\begin{abstract}
In a modern day competitive business environment, retailers can not rely only on conventional forms of marketing. It is important to find new original ways to influence the consumers. That is why many retailers turn to a new area of marketing called sensory marketing. The present study uses scent marketing techniques to investigate hedonic perception and verbal affective response of foreigners towards Chinese culture-specific odors. Our research has employed participants from over 40 countries to analyze the perception of Chinese odors. In this study, we attempt going beyond the stimulus-organism-response (SOR) model. Our findings reveal that culture, ethnic origin, duration of stay and association with Chinese culture are important variables in culture-specific odor perception. We further claim that consumer perception of smell is moderated by past experience and self-association with the culture. Our results suggest that odor affective response involves a complex emotional process. These emotions, are formed by the amount of interactions with a particular odor and context in which the odor is experienced.
\end{abstract}

Keywords: scent marketing; hedonic perception; cross-culture; Chinese culturespecific odor.

\section{SENSORY MARKETING. INTRODUCTION.}

There is a fierce competition between retailers: more and more shops are opening every day creating a wider variety of choices for the customers. On top of this, nowadays consumers are overloaded with information and do not respond to the traditional explicit marketing tools anymore. According to the Harvard Business Review, everyday consumers are bombarded with three thousand advertising messages. Consumers tend to be irrational when making purchasing decisions, they are not only buying goods because of their functionality but rather, as reported by The Economist (2008), looking for emotional and sensorial experience from the purchasing process. Moreover, as Bloch et al. (2003) states the quality of products continues to increase, which makes consumers focus more on the aesthetic dimensions of a product. To attract and hold a particular segment of market retailers have to use different marketing tools: from improving customer service and to creating pleasant store atmosphere. Researchers have found that experience of the purchase and emotional connection with the brand can be built by appealing to human mind and senses (Hirschman and Holbrook, 1982; Hultén, 2011). Thus, in recent years, a new field of marketing, sensory marketing, is getting more and more popular among retailers to attract customers and enhance their shopping experience. Professor Aradhna Krishna, who is considered to be the pioneer of the field of sensory marketing, defines it as "marketing that engages the consumers' senses and affects their perception, judgment and behavior." (Krishna, 2010, p 1). Krishna (2010) further notes that sensory marketing enables retailers to influence consumers' emotions, memories, preferences and choices through all five 
sense. While some senses, like sight and hearing, are heavily overused by the retailers, others, like smell, in particular, are not widely utilized, although it is argued that olfactory cues are the most salient upon entering a store. According to Bradford and Desrochers (2010) scent marketing or aroma marketing is a relatively new area of marketing, and there is still a limited number of academic research investigating its influence on consumers, or more precisely comparing effects of scents on the consumers with different cultural backgrounds, which we will explore in this study. The sense of smell may be of particular interest for marketers, as you think before responding with all other senses, but with scent, you react subconsciously. Smell has a subconscious impact on the customer's behavior. Odor can affect a person's mind without him or her being conscious of it, "smell is something that the customer cannot ignore" (Ward et al., 2003, p.295), after all, we can not stop breathing. In their research multiple authors have proven that a mere presence of a pleasant smell is a low-cost and efficient way of intensifying consumers' positive experience in the service environment (Chebat and Michon, 2003; Spangenberg et al., 1996). Retailers, hotels, casinos, airplane companies invest millions of dollars hoping to create distinctive, pleasant smells which will help attract consumers and create memorable brands. Lindstrom (2005) argues that once senses are involved, customers feel a stronger connection with the particular brand, thus willing to pay more. According to Scent Marketing Institute companies in many industries such as hospitality, retail, consumer packaged goods, beauty, health care, real estate, entertainment, etc. employ sensory marketing technique in their operations to create comfortable business environments for their customers. Many firms provide service of creating unique signature smells for business owners, which as many scholars believe enables them to distinguish their business offers from other competitors and helps them win consumers brand loyalty and makes consumers pay more (Spence, 2002; Davies et al., 2003). Nowadays there are dozens of aroma marketing companies worth millions of dollars, whose consultants help choose a perfect fragrance for a particular business or develop a customized one for use in the service outlet.

\section{LITERATURE REVIEW}

\section{Ambient scent and environmental psychology}

Kotler (1974) states that in retail store atmosphere is a highly relevant tool. In his study, he defines atmosphere as the "air surrounding the sphere" or more colloquially as the quality of surrounding space. He further notes that the atmosphere itself is a more important factor in creating a positive experience for the customer which will lead to the purchasing decision than the product itself.

Mehrabian and Russell's (1974) model is the fundamental model used in many studies on the effect of environmental factors in the retail environment on customer behavior. The idea behind Mehrabian and Russell's model emerged from the field of environmental psychology. They propose that variables of the surroundings have an impact on people's emotional responses to these surroundings, which in turn determines whether people approach or avoid the surroundings. Mehrabian and Russell (1974) further argue that emotional responses combine three dimensions, namely pleasure, arousal, and dominance.

Russell and Pratt (1980) proposed another model on emotional responses, the so-called PA model. In their marketing research they argue that emotions construct only two dimensions: pleasure - arousal.

\section{Odor presence and pleasantness}

Multiple research has found a direct connection between our behavior and scent pleasantness. It is believed that the right scent can positively affect consumers' behavior. Bone and Ellen 
(1999) have found that background ambient odors can influence customers' intentions to visit and return to a store, as well as, according to Chebat and Michon (2003) encourages consumers to perceive a shopping center in a positive way and, indirectly, recognize products as those of higher quality. Ambient odors also can be used to send out a message to the consumers on the kind of product being sold, something that specialty stores such as bakeries and coffee shops have utilized for a long time. Gulas and Bloch (1995) point out that scents influence consumers in different ways, not only attract the customers, but also, disgust them, and, therefore, consumers refuse to shop or spend time in a particular store (so-called avoidance behavior). It is proposed that having a pleasant scent may result in positive affective or behavioral responses, while having an unpleasant odor may result in negative emotional or behavioral responses (Mitchell et al., 1995; Bone and Ellen 1999; Morrin and Ratneshwar 2000).

Although effects of ambient scent have not been researched much in academia, there are studies with valuable contributions in this area. One of the notable studies by Hirsch (1995) found that when a pleasant scent is diffused in a casino, gamblers tend to spend more time and money on the slot machines. Another study by Spangenberg et al. (1996) reproduced retail environment to examine the effect of ambient scents on consumers. It was found that the study participants evaluated scented environment less negatively than unscented, and a rather surprising finding was that even effectively neutral scents produced a positive effect. What is interesting, not excessive scent intensity did not produce any effect on the final results. Yet in one more empirical study by Bone and Ellen (1994), where participants were asked to do a catalog-shopping task in scented and unscented rooms, it was found that they would take more time on the task in a scented environment.

\section{Emotional effect of scents on consumers}

Holland, Hendriks, and Aarts (2005) propose that smell influences consumer behavior and attitudes in many ways. Ambient scent may trigger sensations that create or heighten an appetite for certain goods, services or experiences. According to the research institute of Millward Brown (2005) sense of smell evokes 75\% of our emotions. Dember and Warm (1991) claim that through our sense of smell marketers have the potential to create moods and influence feeling. In Kotler (1974), once retailers have noticed that it is hard for a consumer to simply walk by a bakery withholding oneself from purchasing a freshly baked bread, they started using the smell of fresh bread to influence the customers. In a similar study Hirsh (1991) revealed that this way they could increase not only the consumption of bread products but also consumption of other products available in the store. However, not just any kind pleasant smell has a positive effect on customers. Recent research by Hermann et al. (2013) has compared the complexity of smells and revealed that simple smells are more fluent and impact consumer responses, or to be more precise, result in more significant spending.

\section{Scents and congruency}

It was also found that in order to improve the store environment and engage customers in a more approach behavior, pleasant scents need to be congruent with the store's offerings. It is rather important to pay attention to whether the scent is thematically appropriate for the store's products. Research by Douce et al. (2013) have examined bookstore customers and found that they were more likely to browse and, as a result, purchase romance and cookery books in the presence of a chocolate smell. Books thematically incongruent with the chocolate scent (e.g. crime, travel, and business related books) were much less likely to be purchased. Further evidence on congruency was found in a study by Spangenberg (2006), who revealed that congruency of scent and customers' gender lead to more positive feedback in a retail store environment. In another study on congruency Mattila et al. (2001) have found that arousing 
qualities of ambient stimuli, if matched, produce a more positive effect. To test their hypothesis the researchers manipulated congruency of arousing qualities of ambient scent and music. They found that there had to be a coherency of arousing qualities of music and the scent in order for consumers to perceive the retail environment as more pleasant. That is if the music is fast, then the sent has to be stimulating, and if the music is slow, then the scent has to be relaxing. The authors of the study further claim that this results in a more positive effect on consumer behavior and makes them more content with the store environment, therefore, leads to its higher assessment. The results of another experiment by Spangenberg (2004) prove the findings of the research mentioned above: consistency between an ambient scent and music in a retail setting leads to customers evaluating the store, the line of product and the environment as more favorable. Furthermore, the cohesion of ambient scent and music also had a positive effect on behavioral intentions to visit the store. When the ambient scent and music are incoherent, however, there is either no or negative impact on store environment assessment or evaluations and behavioral intentions.

\section{Scents and memory}

In Dowley (2008), smell is the most acute of all senses in terms of connection to our emotional recollection. Strong emotional responses arise from smells: while scents associated with a positive experience can bring us joy, odors that remind us of a negative experience may lead to aversion behavior. Several studies by have revealed that when compared to memories triggered by visual, auditory, and tactile stimuli memories triggered by odor stimuli were considerably more emotional and precise (Herz and Cupchick, 1995; Herz, 1996, 1998b). According to Proust (1982) the smell evoked experience of being carried away into childhood memories is referred to as Proust phenomenon. An example being often quoted from Proust is when the author dips a biscuit in a cup of tea smells it and immediately gets carried away into his childhood memories.

According to the Sense of Smell Institute, human visual recollection is about 50\% after three months, while the sense of smell evokes memories with higher accuracy and for a longer period, $65 \%$ accuracy for the whole year. People of different cultures have different ideas and memories about smells. While the smell of tangerine and Christmas tree may evoke memories of celebrating New Year in the post-Soviet Union countries, it may mean nothing to somebody from Asia. Or smell of cinnamon and gingerbread associates with Christmas in the West, while it does not mean much to most of the people in post-Soviet Union countries. Following the example of Western cinemas, one of the cinemas in Russia decided to fill their halls with a cucumber-mint scent, which is believed to help people concentrate. As it turned out, Russian consumers associated this scent with a perfume called "Cucumber" so popular in the Soviet Union. Instead of feeling refreshed, people were irritated. Thus, Classen et al. (1994) claims that olfactory sensation is not the only ingredient in the cognition of smells, equally important are the experiences and feelings evoked by them.

\section{Product scent}

In order to enhance product experience, producers can manipulate all of its features including odor. However, as we can see from the literature review above research in scent marketing has primarily focused on ambient scents and their influence on the consumers. Still, it seems that retailers employ product scent more in the marketplace. Krishna (2010) argues that while the ambient scent is diffused all over the store environment and it's highly likely not correlated with any particular product, product scent, on the other hand, seems to be a more efficient tool for communicating product information to the consumer. It makes a product distinctive, and the memory of it lingers in the mind of consumers. 
One of the first studies on product scent and its evaluation by consumers conducted by Laird (1932) revealed that when given a choice of scented and unscented silk stocking women tend to choose scented stockings over unscented. Nowadays many retailers use product scents for initially unscented products (from MP3 players to telephone cards) to enhance consumers' experience. The smell assists consumers in product evaluation. Mitchell (1994) claims that consumers may perceive odor as a physical product attribute which will increase the possibility of positive evaluation. Findings of another study by Bone and Jantrania (1992) suggest that products are evaluated more positively when scented, on the condition that the scent is congruent with this product. In their study, the researchers showed that when being presented with a coconut and a lemon scent and two products, sunscreen lotion and cleaning detergent, consumers preferred products with appropriate scents, coconut scent for lotion and lemon scent for the detergent. However, these findings seem to be inconsistent. In a more recent study on product and scent congruency Schifferstein and Michaut (2002) tested odors for three different categories of products. Quite unexpectedly, odor congruency did not affect overall product evaluation. Yet another study by Ellen and Bone (1998) revealed that when odors of scented pages in a magazine were not congruent with an advertisement they produced an adverse effect on the consumers, however, a congruent odor had no significant effect.

\section{Hedonic perception}

\section{HYPOTHESIS DEVELOPMENT}

Once we experience an odor our reaction is straightaway, we approach or avoid it. Olfactory scientists like Carterette (2013) regard our liking or disliking of certain odors as odor hedonics. Richardson and Zucco (1989) conclude that since our liking and disliking are closely connected, our preferences are based on hedonic perception. Carrasco and Ridout (1993) measure hedonic perception on three components: pleasantness, familiarity, and intensity. There is a strong relationship between pleasantness and familiarity in terms of odor preference perception, meaning that "familiar odors tend to be better liked than unfamiliar odors, and pleasant odors are often perceived as familiar" (Herz, 2004, p.3). It is believed that intensity is correlated with pleasantness in a more complex way (Moskowitz et al., 1976, Sulmont et al., 2002). In Herz (2004), odor intensity and our affective odor perception depend on how intense the odor is, while a strong unpleasant odor is unacceptable, a weak one might be accepted.

We would like to test the notion that "familiar odors tend to be better liked than unfamiliar odors, and pleasant odors are often perceived as familiar" (R.S. Herz 2004, p.3) in our setting. That is test how foreigners who have lived in China for some period of time perceive Chinese culture specific odors. We assume that participants who stayed in China for a longer period of time will perceive Chinese culture-specific odors as more pleasant and familiar. We hypothesize that the longer a person stays in China the more pleasant he or she finds Chinese culture-specific odors. For example, those who stayed in China for more than five years will find odors as much more pleasant and familiar than those who stayed for less than a year. On the other hand, participants who stayed in China for less than a year and 1-2 years might not have any significant differences. Based on the discussion above we conclude:

H1: the more pleasant Chinese culture specific odors, the more familiar they are.

H2: the more familiar Chinese culture specific odors, the more pleasant they tend to be.

\section{Olfactory adaptation and associative learning}

Every day we are surrounded by a broad spectrum of olfactory stimulation. Yet, it is essential to stay sensitive and responsive, in other words, be able to adapt. Dalton et al. (2000) argues 
that sensory adaptation plays a significant role in the human life; it allows us to adjust to the surroundings and respond appropriately to its changing conditions. Zufall and Leinders-Zufall (2000) further claim that when we are continuously exposed to an odor or exposed to it for an extended period of time, our olfactory sensitivity to that odor diminishes, however, we are able to regain the sensitivity in the absence of the odor. In their works scholars explain the factors that influence adaptation process (Brglund, 1974; Cain, 1974). The first factor that stimulates and influences adaptation process is the duration of exposure to odor. It influences to what extent and how fast we are able to adapt to certain stimuli. The second factor is the concentration of the adapting odorant, which determines the observed degree of adaptation. Possessing similar characteristics to other sensory systems olfactory adaptation is still somewhat different. First of all, as Herz and Engen (1996) claim, it is rather durable and may be changed due to the chemical properties of the odorant molecules. What is interesting, adaptation may be impacted if a person was exposed to a similar odor in the past, the process known as cross-adaptation. Scholars Stevenson and Boakes (2003) have proved that humans can adapt to similar smelling odors. Therefore, we assume, that people who more closely associate themselves with Chinese culture will be better adapted to the odors that we will present in our experiment, which leads us to believe they will be more familiar with the odors and find them more pleasant.

Scholars propose two theories on human odor hedonic perception. The first theory is that once we are born, we are programmed to like or dislike a particular smell. Mandairon et al. (2009) supporting this theory found that mammal species (humans and mice) partake same odor liking, further pointing out that these likings are determined by physicochemical features of odorant stimuli. The second theory states that our experience predetermines how we perceive a particular scent. Scents which we find pleasant happen to be learned about during enjoyable activities. On the other hand, unpleasant smells are unpleasant because we learn about them from unpleasant events. T. Engen and E.A. Engen (1997) supporting the learned view of olfactory perception believe that although we possess an inborn ability to respond to olfactory stimuli depending on certain stimuli or a situation, once we come across this odor a feeling gets attached to it, that is we learn about this odor through experience. In their experiment the researchers tested newborn infants' hedonic perception. It was found that infants showed no differentiated responses to pleasant and unpleasant odors, and it was impossible to predict their responses based on adults' responses. In a subsequent experiment the authors tested odor preferences of four-day-old infants, and found that the infants failed to discriminate ecologically meaningful odors, that is mother perfume that she had been wearing during the feedings. They further conclude that this mother-child attachment is formed later on through experience. Other scholars like Macfarlane (1975) also find this ability to discriminate odors more consistent over time. Engen and Corbit (1970) conclude with the increase of exposure to different stimuli, child's odor likes and dislikes become more varied.

According to Rozin and Millman (1987) we learn to like and dislike certain things. Our lives are largely affected by our preferences, from social interaction to the consumption of goods. Sherer (1993) argues that once we experience objects or events from the past once more, exact same emotion reappears again. The concept of associative learning lies behind the learned view of odor hedonic perception. Abramson (1994, p. 38) defines associative learning (or conditioning) as "a form of behavior modification involving the association of two or more events, such as between two stimuli, or between a stimulus and a response". Herz (2004) explains the mechanism of associative learning: unconditioned stimulus (emotion) is matched with conditioned stimulus (odor), later on the odor is able to evoke the emotion and behavioral changes. An example of olfactory associative learning provided in a study by Robin et al. (1998) 
involves humans. In their study researchers tested odorants from the dental office and its effect on the patients. Two groups of patients were compared: those who were frightful of the dental care and those who were not. It was found that the patients who dreaded their experience in the dental office were more likely to show more discomfort and fear when inhaling the odors and perceived them as more unpleasant. Apparently, they associated the smell with their painful memories that they experienced in the dental office. Odors, as a part of associative learning, not only evoke emotions from past experience and have an influence on mood but also, determine how we perceive these odors. Thus, we hypothesize that foreigners who generally have a more pleasant perception of Chinese culture and associate themselves more with it will evaluate Chinese specific-odors as more pleasant and more familiar. We further propose that these odors will evoke more pleasant feelings (happiness, energy, etc.).

In experiments with novice and veteran perfume makers, French scientists Plailly et al. (2012) found that the ability to detect and identify hundreds, even thousands, of different odors depends almost entirely on rigorous training. This leads us to believe that once a human is exposed to an odor on a daily basis, she is able to identify this odor as more familiar, that's why we believe that the duration of stay will have a positive impact on odor identification. Crosscultural studies prove that associative learning defines our olfactory preferences. So far there has been no empirical evidence of similar odor evaluations across cultures. Different cultures prefer different odors, which further supports the idea of learned odor perception. Crosscultural study by Schleidt et al. (1981) on odor hedonic perception show differences in both common and offensive odors. While stinky tofu may be a popular dish in Southeast Asia, we can assume that many westerners may resent it. From the discussion above we would like test the following hypothesis:

H3: Duration of stay has a positive effect on average pleasantness, familiarity and feelings toward Chinese culture specific odors.

H4: Association with Chinese culture has a positive effect on average pleasantness, familiarity and feelings toward Chinese culture specific odors.

\section{Conceptual framework}

\section{METHODOLOGY}

Based on the literature review we were able to form the following conceptual framework:

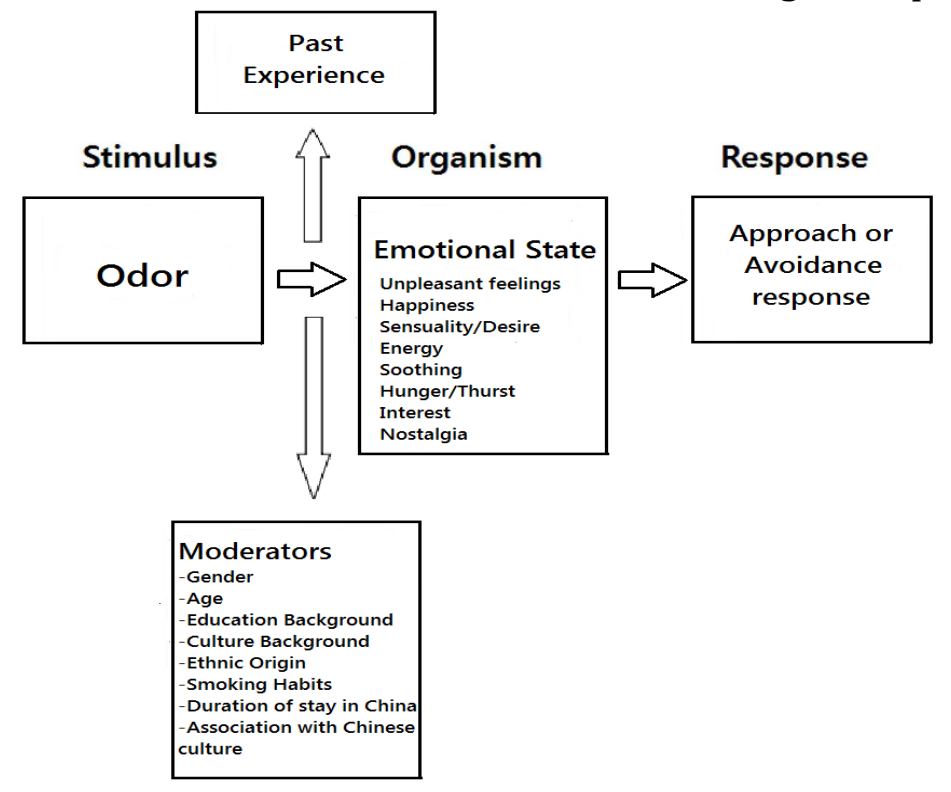

Figure 1. Conceptual framework 


\section{Participants}

We tested the hypothesis by conducting an experiment. The sample for it consisted of 166 participants who were mostly students (93 males, 73 females). Due to incomplete responses and reported previous history of smell impairments 34 participants were excluded from the analysis. This resulted in a final sample of 132 (85 males, 47 females). Most of the participants were students, and some came to work in China.

Our sample consisted of three age groups: under 18, 19-29, and 30-40. Age of most of the participants ranged from 19 to 29 ( $81 \%$ of the sample).

Most of the participants were non-smokers, 17\%, however, reported to be smokers.

We were able to employ participants from 40 countries, and further divided our sample in four culture groups and nine ethnic groups.

Most of the participants were Asian (53\%), following European (24\%) and African (17\%). North American presented the smallest group (6\%)

All of the participants were born outside of China but had spent from several months to more than five years in China. Most of the participants stayed in China for less than year (32\%), whereas the smallest group presented in the sample (7\%) stayed in China for more than 5 years. The sample comprised of equal number of participants in groups "1-2 years" and "2-3 years", 23\%, while participants who stayed in China from 3 to 5 years comprised $15 \%$.

Participants were asked to rate their self-association with Chinese culture on a scale from 1 to 10 (1 - being lowest self-association, 10- highest self-association). Based on the responses the sample was further divided into three groups: low (1-3), moderate (4-6), and high selfassociation (7-10).

Most of the experiment participants reported moderate self-association with Chinese culture (43\%), while low self-association was reported in 31\% of those surveyed. The experiment revealed that $26 \%$ of respondents possess low self-association with Chinese culture. The results are presented in the graph below:

\section{Procedure}

The study was conducted in a lab environment. An experiment in a lab was chosen over a field experiment as it is easier to prevent odors from combining with other ambient scents. Therefore, we could control the course of the experiment and obtain more precise results. Scent samples were presented in small glass bottles in fluids and coded with letters A-H so that participants were not able to distinguish the odors based on their name or appearance. An empirical study by Herz and von Clef (2001) revealed that if there are labels provided for the odors, it can create olfactory illusions and affect hedonic perception. When an odorant was given a positive label, the odors were perceived as more pleasant and familiar. Interestingly enough, one same odor (isovaleric and butyric acid) when first labeled "parmesan cheese" was evaluated as edible, however when named "vomit" participants showed negative evaluations.

The participants were allowed to sniff each sample as many times as they wanted and then rate its pleasantness and familiarity on a 10-point scale $(1$ - not at all pleasant/familiar to 10 extremely pleasant/familiar). Cronbach's $\alpha$ for the scale of pleasantness and familiarity is 0.825 and 0.701 accordingly. Participants were also presented with a list of 8 affective terms 
and asked to choose one term from the list which represented the feeling evoked by the sample they smelled. The terms included: Unpleasant feelings (Disgust/Irritation), Happiness/Wellbeing, Sensuality/Desire, Energy, Soothing/Peacefulness, Hunger/Thirst, Interest, and Nostalgia.

Two other important dependent variable measured were "duration of stay in China" and "association with Chinese culture". Participants had to choose their duration of stay from "less than a year" to "more than five years" and rate how close they associate themselves with Chinese culture on 1 (not at all close) to 10 (extremely close) scale.

\section{Odor samples}

A survey was conducted to determine odors that would represent a range of Chinese culturespecific food odors. Thirty-five people (22 Chinese and 13 foreigners) were asked to name three odors that in their opinion would best represent China. We also took a closer look at Chinese culture and found that Chinese people have a saying: "Firewood, rice, oil, salt, sauce, vinegar and tea are the seven necessities to begin a day." Not only that these seven items are deeply rooted in Chinese culture, but you can also find them, except for firewood, in modern Chinese homes. We chose four odors from seven necessities and four /more from our survey. A total of eight odors were selected for the experiment. The scents included: stinky doufu, white wine, green tea, Chinese traditional medicine herbs, sesame oil, soybean milk, black vinegar, and soy sauce.

\section{One-way ANOVA}

\section{RESULTS}

First, we conducted a one-way between subjects ANOVA with gender, age, country of origin, ethnic origin, smoking habits, degree of education, duration of stay in China, association with Chinese culture as dependent variables and odor pleasantness and odor familiarity as independent variables.

\section{Gender}

On average women and men did not significantly differ in the ratings of odor pleasantness ( $\mathrm{F}(1$, $131)=1.440, \mathrm{p}=0.232)$ and familiarity $(\mathrm{F}(1,131)=2.160, \mathrm{p}=0.144)$. However, a T-test revealed slight differences; women tend to rate odors slightly more pleasant and familiar. Taking a closer look at the rating of each odor, we found a significant difference in evaluation of sesame oil $(F(1,131)=5.030, p=0.027)$ and soy sauce $(F(1,131)=5.239, p=0.024)$. Women found both of these odors more pleasant and soy sauce more familiar $(F(1,131)=4.791, p=0.030)$. "Gender" group statistic is presented in the table below:

\begin{tabular}{|c|c|c|c|c|c|}
\hline & & $\mathrm{N}$ & Mean & Std. Deviation & $\begin{array}{c}\text { Std. Error } \\
\text { Mean }\end{array}$ \\
\hline \multirow{2}{*}{ PLEASANTNESS } & male & 85 & 5.5277 & 1.55386 & .16854 \\
\cline { 2 - 6 } & female & 47 & 5.8116 & 1.53258 & .22355 \\
\hline \multirow{2}{*}{ FAMILIARITY } & male & 85 & 6.8101 & 2.14551 & .23271 \\
\cline { 2 - 6 } & female & 47 & 7.4073 & 2.38897 & .34847 \\
\hline
\end{tabular}

Table 1: “Gender" group statistic

\section{Age}

There were some significant differences between age group "under 18" and "19-29 years old". Average pleasantness between the age group "under 18" and age group "19-29" is significantly different at the $p=0.045$, and average familiarity at the $p=0.028$. In particular, pleasantness of white wine $(p=0.48)$ and herbs $(p=0.019)$ was significantly different, as well as familiarity of 
herbs $(\mathrm{p}=0.006)$, sesame oil $(\mathrm{p}=0.022)$, and soybean milk ( $\mathrm{p}=0.041)$. Groups " $19-20$ " and " 30 40 " differed only in the evaluation of vinegar pleasantness $(\mathrm{p}=0.26)$. Although, in Chebat, Morrin and Chebat (2009), researchers were able to demonstrate that age produced a moderating effect on consumers' shopping experience, our results are, rather, inconsistent and do not provide an opportunity for any conclusion.

\section{Education background}

The degree of the participants' education had no effect on their perspective of pleasantness and familiarity of the culture-specific odors. Except for level of familiarity of soy sauce, participants with Ph.D. were different from all other groups $(\mathrm{p}=0.015)$.

\section{Smoking habits}

On average, smoking habits did not seem to have much effect on the degree of the pleasantness of both pleasant and unpleasant odors. The difference was found in the ratings of familiarity of two unpleasant odors. Participants with smoking habits tend to rate unpleasant smells (stinky doufu and white wine) more familiar than non-smokers $(\mathrm{p}=0.016)$. However, no difference in evaluation of familiarity of pleasant odors was found.

\section{Culture}

Cultural background yielded some significant results. Taking Cultural background as a group, we observed significant differences in the pleasantness evaluation for only three out of eight odors. In particular, stinky doufu $(\mathrm{F}(3,128)=2.937, \mathrm{p}=0.036)$, vinegar $(\mathrm{F}(3,128)=3.073$, $\mathrm{p}=0.030)$, and soy sauce $(\mathrm{F}(3,128)=10.903, \mathrm{p}=0.036)$. As for the average familiarity, most of the odors showed significant differences (five out of eight). These odors include stinky doufu $(F(3,128)=2.847, p=0.04)$, herbs $(F(3,128)=4.472, p=0.005)$, sesame oil $(F(3,128)=3.506$, $p=0.017)$, vinegar $(F(3,128)=4.255, p=0.007)$, and soy sauce $(F(3,128)=9.259, p=0.000)$.

Let's consider the differences between culture groups.

Asian and European. Pleasantness of the following odors was significantly different: stinky doufu $(p=0.006)$, green $(p=0.042)$, sesame oil $(p=0.012)$, soy sauce $(p=0.000)$; and familiarity of all the odors except for green tea, stinky doufu $(\mathrm{p}=0.032)$, white wine $(\mathrm{p}=0.032)$, herbs $(\mathrm{p}=0.001)$, sesame oil $(\mathrm{p}=0.004)$, vinegar $(\mathrm{p}=0.003)$, soy sauce $(\mathrm{p}=0.000)$.

African and European. The pleasantness of the following odors was significantly different: white wine $(p=0.024)$, soy sauce $(p=0.000)$; and familiarity of stinky doufu $(p=0.006)$, green tea $(\mathrm{p}=0.026)$, vinegar $(\mathrm{p}=0.002)$, and soy sauce $(\mathrm{p}=0.000)$.

Asian and North American. Pleasantness of the following odors was significantly different: vinegar ( $\mathrm{p}=0.006)$, and soy sauce $(\mathrm{p}=0.01)$; and no significant difference in familiarity.

African and North American. The pleasantness of the following odors was significantly different: vinegar ( $p=0.044)$, and soy sauce $(p=0.03)$; and familiarity of soy sauce $(p=0.042)$.

North American and European. There was only one significant difference in the green tea odor familiarity ( $\mathrm{p}=0.048)$, and no significant difference in the odor pleasantness.

As we can see from results were significantly different between Asian and European group. We can assume that these differences can be explained by geographic location of the cultures, as they are geographically closer the less differences there are. 


\section{Ethnic origin}

Ethnic origin had a major impact both on the participant evaluations of pleasantness ( $\mathrm{F}(8$, $121)=3.879, \mathrm{p}=0.000)$ and familiarity $(\mathrm{F}(8,121)=5.302, \mathrm{p}=0.000)$.

On average, taking ethnic origin as a group pleasantness, levels of half of all odors were significantly different (stinky doufu $(F(9,123)=5.097, p=0.000)$, white wine $(F(9,123)$ $=4.791, p=0.000)$, sesame oil $(F(9,123)=3.039, p=0.004)$, soy sauce $(F(9,123)=6.191$, $\mathrm{p}=0.000)$ ).

Interestingly enough the results show that Central Asian group is different in the preferences from 6 out of 8 ethnic groups. Taking into consideration only "ethnic group" variable we can assume that pleasantness level of this ethnic group is higher than the others due to the regional closeness to China. It is still not as high as South-East Asian groups as there are more cultural differences.

Quite unexpectedly, South-East Asian was different only from other Asian ethnic groups. These results demonstrate that although regional closeness plays an important role in people's odor and food preferences, each ethnic group within one region has its one cultural, religious traditions, etc.

On average taking ethnic origin as a group familiarity levels of most of all odors were significantly different (stinky doufu $(F(9,123)=4.828, p=0.000)$, herbs $(F(9,123)=5.165$, $\mathrm{p}=0.000)$, sesame oil $(\mathrm{F}(9,123)=4.694, \mathrm{p}=0.000)$, soybean milk $(\mathrm{F}(9,123)=3.591, \mathrm{p}=0.000$, vinegar $(F(9,123)=67.516, p=0.000$, soy sauce $(F(9,123)=6.362, p=0.000))$.

Analysis between ethnic groups of both pleasantness and familiarity revealed that despite regional closeness of certain groups, we can not neglect the fact that each ethnic group has its own traditions, religion and cuisine. For example, South and West Asia. Despite the fact that these ethnic groups share one religion, nevertheless we could still observe differences in preferences and familiarity of Chinese culture-specific odors.

\section{Duration of stay in China}

Duration of stay on average did not seem to affect participants' feelings of pleasantness much. On average Post-hoc LSD analysis revealed some significant differences between participants who stayed in China for 1-2 years and 2-3 years $(\mathrm{p}=0.035)$, as well as $1-2$ years and 3-5 years $(p=0.021)$. Taking a closer look at the effect of duration of stay in China on each odor pleasantness, there were no differences found.

Duration of stay produced big effect on odors' familiarity. All the odors except for tea and milk are significantly different in familiarity $(F(4,128)=6.017, p=0.000)$. Comparative analysis within the different duration of stay groups revealed that there is a significant difference between groups of relevantly short (less than a year, 1-2 years) and long (2-3 years, 3-5 years, and more than five years) duration of stay. There were not any differences between participants who had spent "less than one year" and "1-2 years", as well as between groups "23 years", "3-5 years", and "more than five years". We then conducted an LSD comparative analysis between all the groups for each odor familiarity. The pattern is consistent throughout all the odors, both pleasant and unpleasant. 
P-values of the significant differences between the groups are presented in the table below:

\begin{tabular}{|c|c|c|c|}
\hline & $2-3$ years & $3-5$ years & More than 5 years \\
\hline Less than a year & $\mathrm{p}=0.011$ & $\mathrm{p}=0.002$ & $\mathrm{p}=0.025$ \\
\hline $1-2$ years & $\mathrm{p}=0.001$ & $\mathrm{p}=0.000$ & $\mathrm{p}=0.006$ \\
\hline
\end{tabular}

Table 2: Comparison of significant differences for different duration of stay groups

All the odors' familiarity, except for green tea and sesame oil, was significantly different (stinky doufu $(F(4,128)=4.535, p=0.002)$, white wine $(F(4,128)=2.766, p=0.03)$, Chinese traditional medicine herbs $(F(4,128)=3.283$, $p=0.013)$, soybean milk $(F(4,128)=3.967, p=0.005)$, vinegar $(F(4,128)=3.806, p=0.006)$, and soy sauce $(F(4,128)=2.555, p=0.042))$.

\section{Self-association with Chinese culture.}

It was found that self-association with Chinese culture greatly affected respondents' ratings of both pleasantness and familiarity $(\mathrm{p}<0,001)$.

\begin{tabular}{|c|c|c|c|c|c|c|}
\hline & & Sum of Squares & df & Mean Square & F & Sig. \\
\hline PLEASANTNESS & Between Groups & 45.754 & 2 & 22.877 & 11.030 & .000 \\
\hline & Within Groups & 267.547 & 130 & 2.074 & & \\
\hline FAMILIARITY & Total & 313.300 & 132 & & & \\
\hline & Wetween Groups & 80.471 & 2 & 40.235 & 8.956 & .000 \\
\hline & Total & 659.993 & 132 & & & \\
\hline
\end{tabular}

Table 3: Correlation of average self-association with Chinese culture and pleasantness/familiarity

On average self-association affected pleasantness of all odors, except for white wine, stinky doufu, and green tea. It also influenced average familiarity of all odors, except for white wine, vinegar, and soy sauce.

On average pleasantness and familiarity of the odors are different in groups with low and high self-association, as well as groups with moderate and high self-association. There is no significant difference, however, between groups with low and moderate self-association. There is also no significant difference in the pleasantness of the two unpleasant scents: stinky doufu and white wine. These odors scored low with all three groups of participants, with slightly different average scores (Mlow=2, Mmoderate=2.14, Mhigh=2.54) for stinky doufu and (Mlow=3.17, Mmoderate=3.26, Mhigh=3.63) for white wine. Although receiving such low scores, there is still a tendency for a slight increase in the pleasantness level together with culture self-association level. The familiarity of these two unpleasant odors grows with the degree of culture self-association: (Mlow=3.98, Mmoderate=5.35, Mhigh=6.94) for stinky doufu and (Mlow=5.44, Mmoderate=5.88, Mhigh=6.94).

Low and high self-association. Most of the odors' pleasantness and familiarity is different between groups with low and high level of self-association (green tea $(p=0.46)$, herbs $(\mathrm{p}=0.009)$, sesame oil $(\mathrm{p}=0.45)$, soybean milk $(\mathrm{p}=0.000)$, and vinegar $(\mathrm{p}=0.009))$.

All the odors' familiarity is significantly different, except for vinegar and soy sauce (stinky doufu $(\mathrm{p}=0.000)$, white wine $(\mathrm{p}=0.26)$, green tea $(\mathrm{p}=0.11)$, herbs $(\mathrm{p}=0.001)$, sesame oil $(\mathrm{p}=0.24)$, and soybean milk $(\mathrm{p}=0.02))$. 
Moderate and high self-association. Half of the odors' pleasantness and familiarity is different between these two groups. In particular, sesame oil $(p=0.002)$, soybean milk $(p=0.000)$, vinegar $(p=0.000)$, and soy sauce $(p=0.007)$. As for the familiarity stinky doufu $(p=0.028)$, herbs $(p=0.006)$, sesame oil $(p=0.002)$, soybean milk $(p=0.004)$ are significantly different.

Low and moderate self-association. Comparison of these two groups yielded even fewer differences. Evaluations of the pleasantness of only one odor are significantly different (vinegar $\mathrm{p}=0.02$ ), and two odors (stinky doufu $\mathrm{p}=0.046$, and green tea $\mathrm{p}=0.016$ ) for familiarity.

Thus, we can see the greater there is gap between groups with different self-association levels the more there are differences in evaluation of pleasantness and familiarity of culture-specific odors.

Mean average scores for all odors for different groups with different self-associations are presented below:

\begin{tabular}{|c|c|c|c|c|c|c|c|c|c|}
\hline & $\begin{array}{l}\text { Degree of self- } \\
\text { association }\end{array}$ & $\begin{array}{l}\text { Stinky } \\
\text { doufu }\end{array}$ & $\begin{array}{l}\text { White } \\
\text { wine }\end{array}$ & $\begin{array}{c}\text { Green } \\
\text { tea }\end{array}$ & $\begin{array}{l}\text { Chinese } \\
\text { traditional } \\
\text { medicine } \\
\text { herbs }\end{array}$ & $\begin{array}{c}\text { Sesame } \\
\text { oil }\end{array}$ & $\begin{array}{l}\text { Soybean } \\
\text { milk }\end{array}$ & Vinegar & $\begin{array}{c}\text { Soy } \\
\text { sauce }\end{array}$ \\
\hline \multirow{3}{*}{ 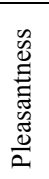 } & Low & 2 & 3.17 & 6.8 & 4.44 & 5.41 & 4.88 & 5.09 & 5.34 \\
\hline & Moderate & 2.14 & 3.26 & 7.16 & 5 & 4.88 & 4.84 & 3.95 & 5.4 \\
\hline & High & 2.54 & 3.62 & 7.82 & 5.74 & 6.51 & 6.97 & 6.03 & 7 \\
\hline \multirow{3}{*}{ 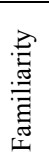 } & Low & 3.98 & 5.44 & 6.63 & 4.19 & 5.44 & 5.32 & 6.51 & 6.19 \\
\hline & Moderate & 5.35 & 5.88 & 7.88 & 4.78 & 5 & 5.56 & 6.47 & 6.61 \\
\hline & High & 6.94 & 6.94 & 8.11 & 6.46 & 6.89 & 7.4 & 7.54 & 7.51 \\
\hline
\end{tabular}

Table 4: Mean average scores for all odors for different self-association groups

The results lead us to believe that the higher self-association with the culture, the higher evaluations of pleasantness and familiarity of culture specific odors.

\section{Multivariate ANOVA}

To further test our hypotheses we analyzed the relationship between our variables using a series of multivariate ANOVAs. Culture, ethnic origin, duration of stay in China, association with Chinese culture, and gender were computed as IVs.

\section{Culture and duration of stay}

Interaction between culture and duration of stay in China produced statistically significant results (Roy's Largest Root $=0.705, \mathrm{~F}=2.975, \mathrm{p}=0.000$ ). The results are presented in the table below:

\begin{tabular}{|c|c|c|c|c|c|}
\hline Variable(s) & Roy's Largest Root & F & Hypothesis df & Error df & Sig. \\
\hline Culture & .139 & $5.182(\mathrm{~b})$ & 3.000 & 112.000 & .002 \\
\hline Duration & .216 & $6.059(\mathrm{~b})$ & 4.000 & 112.000 & .000 \\
\hline $\begin{array}{c}\text { Culture * } \\
\text { Duration }\end{array}$ & .370 & $3.458(\mathrm{~b})$ & 12.000 & 112.000 & .000 \\
\hline
\end{tabular}

Table 5: Correlation of culture and duration of stay 
Test of between-subjects effects showed that variable "culture" has a significant effect on both average pleasantness $(\mathrm{p}=0.022)$ and familiarity $(\mathrm{p}=0.025)$; while the duration of stay in China only affects average familiarity $(p=0.009)$.

\section{Ethnic origin and duration of stay in China}

Variables ethnic origin and duration of stay in China, as well as interaction of these two variables were statistically significant:

\begin{tabular}{|c|c|c|c|c|c|}
\hline Variable(s) & $\begin{array}{c}\text { Roy's Largest } \\
\text { Root }\end{array}$ & F & Hypothesis df & Error df & Sig. \\
\hline Ethnic origin & .469 & $6.506(\mathrm{~b})$ & 7.000 & 97.000 & .000 \\
\hline Duration & .298 & $7.235(\mathrm{~b})$ & 4.000 & 97.000 & .000 \\
\hline $\begin{array}{c}\text { Ethnic origin* } \\
\text { Duration }\end{array}$ & .705 & $2.975(\mathrm{~b})$ & 23.000 & 97.000 & .000 \\
\hline
\end{tabular}

Table 6: Correlation of ethnic origin and duration of stay

Analysis of between-subjects effects showed that ethnic origin has an effect on both average pleasantness $(p=0.000)$ and average familiarity $(p=0.000)$ while the duration of stay in China affected only familiarity $(\mathrm{p}=0.001)$. The combination of ethnic origin and duration of stay in China produced a significant effect on the odors' familiarity.

\section{Culture and association with Chinese culture}

Participants' culture (Roy's Largest Root $=0.123, \mathrm{~F}=4.914, \mathrm{p}=0.003$ ) and association with Chinese culture (Roy's Largest Root $=0.158, F=6.266, p=0.001$ ) had statistically significant effect. Combination of these two variables, however, did not produce any significant effect. Tests of between-subjects effects resulted in culture affecting odors' pleasantness $(p=0.03)$, while association with Chinese culture had an effect both on pleasantness $(p=0.003)$ and familiarity $(\mathrm{p}=0.009)$.

\section{Ethnic origin and association with Chinese culture}

Ethnic origin (Roy's Largest Root $=0.433, \mathrm{~F}=6.811, \mathrm{p}=0.000$ ) and association with Chinese culture (Roy's Largest Root=0.146, F=5.322, p=0.002) were both found statistically significant, a combination of these two variables, however, was not significant. Between-subjects effects test revealed that ethnic origin significantly affects both pleasantness $(p=0.000)$ and familiarity $(p=0.001)$, and association with Chinese culture only has an effect on pleasantness $(p=0.042)$.

\section{Gender and culture}

Combination of gender and culture did not produce any results on any of the dependent variables.

\section{Linear regression}

A linear regression analysis revealed that the coefficients of culture, ethnic origin and selfassociation are significant at level of $\mathrm{p}<0.05$ indicating they have a significant effect on the dependent variable. Estimation of coefficient for culture and association are positive indicating that culture and association have positive impact on average pleasantness, whereas ethic origin has negative impact on average pleasantness.

The estimation of coefficients for duration of stay in China and self-association with Chinese culture are significant at the level of $\mathrm{p}<0.01$ indicating that they have a significant effect on the dependent variable, and the estimation of coefficient for each scale is positive indicating that 
the two variables duration of stay in China and self-association with Chinese culture have positive impact on the average familiarity. Among them, duration of stay in China has more impact on the average familiarity than self-association with Chinese culture and one unit change in duration of stay in China would cause 0.371 unit changes in dependent variable.

\section{Ethnic group's affective verbal response toward Chinese culture-specific odors}

Feelings which each odor evoked were examined for each ethnic group using two-step cluster analysis. The results are presented below:

Ethnic Origin groups are presented as following: 1 South Asian, 2 South-east Asian, 3 West Asia, 4 African, 5 North American, 6 East European, 7 Central Asian, 8 Central European, 9 West European.

Feelings are coded as following: 1 Unpleasant feelings (Disgust/Irritation), 2 Happiness/Wellbeing, 3 Sensuality/Desire, 4 Energy, 5 Soothing/Peacefulness, 6 Hunger/Thirst,7 Interest, 8 Nostalgia.

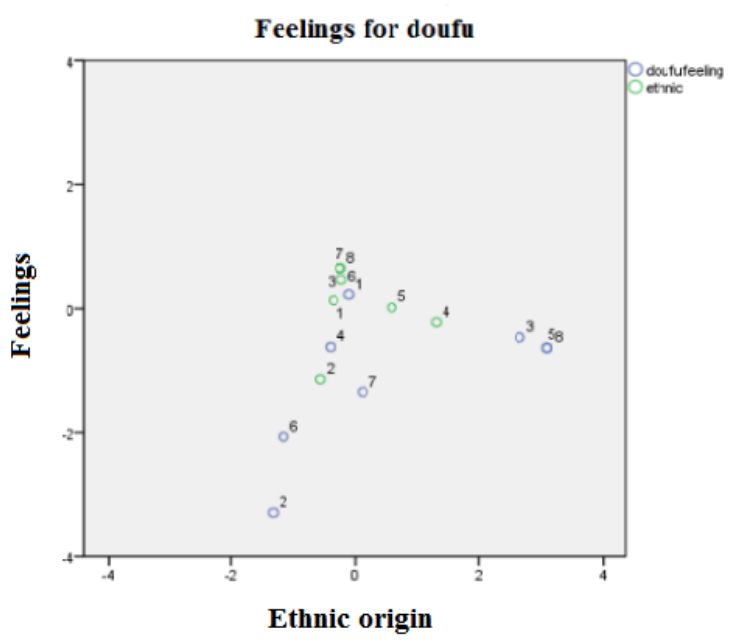

Figure 2: Affective verbal response towards stinky doufu

The graph above shows that when exposed to the smell of stinky doufu South Asian, West Asian, African, North American, East European, Central Asian, and Central European tend to experience 1 (Unpleasant) feelings; South-East Asian tend to experience 4 (Energy); and West European group has no tendency.

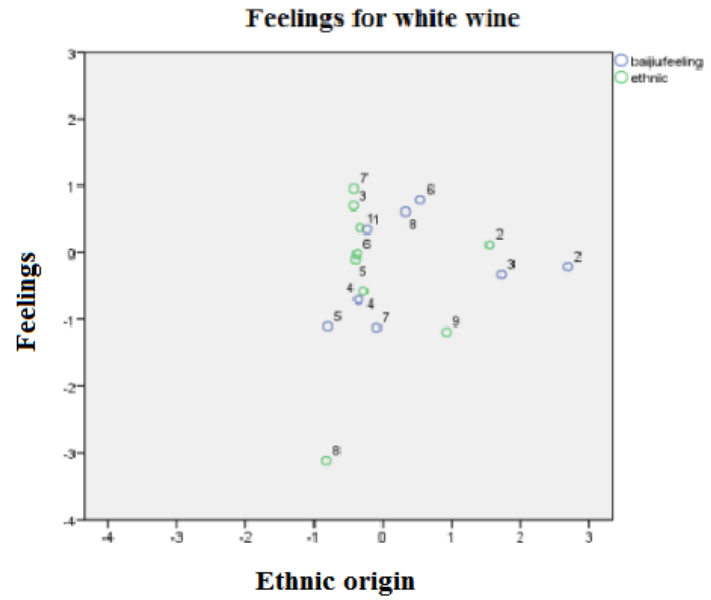

Figure 3: Affective verbal response towards wine wine 
The graph above shows that when exposed to the smell of white wine, South Asian, West Asian, North American, East European, and Central Asian ethnic groups tend to experience 1 (Unpleasant) feelings; South-East Asian tend to experience 3 (Sensuality/Desire); African tend to experience 4 (Energy); Central European group has no tendency; West European tend to experience 7 (Interest).

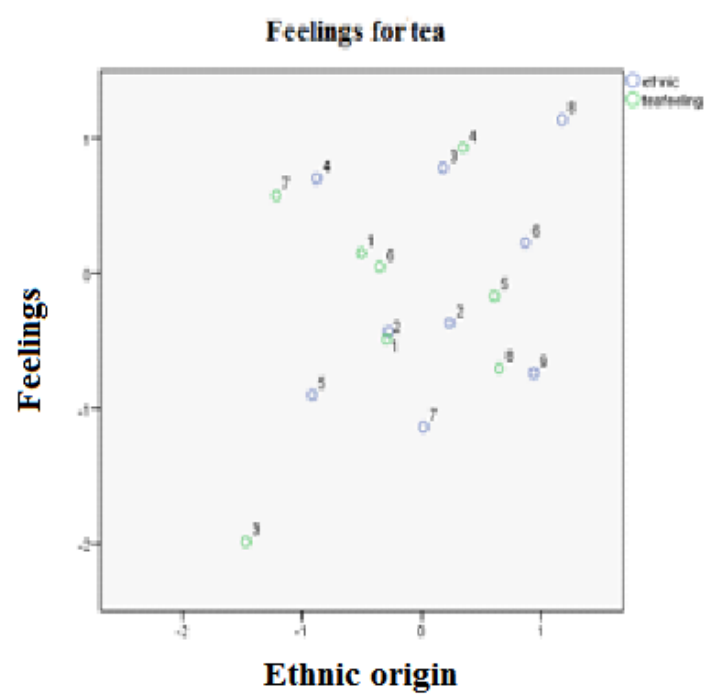

Figure 4: Affective verbal response towards green tea

The graph above shows that when exposed to the smell of Chinese green tea, South Asian and North American ethnic groups tend to experience 2 (Happiness/well-being); South-East Asian and East European tend to experience 5 (Soothing/Peacefulness); West Asian, African, and Central European tend to experience 4 (Energy), both Central Asian and West European groups tend to experience 8 (Nostalgia).

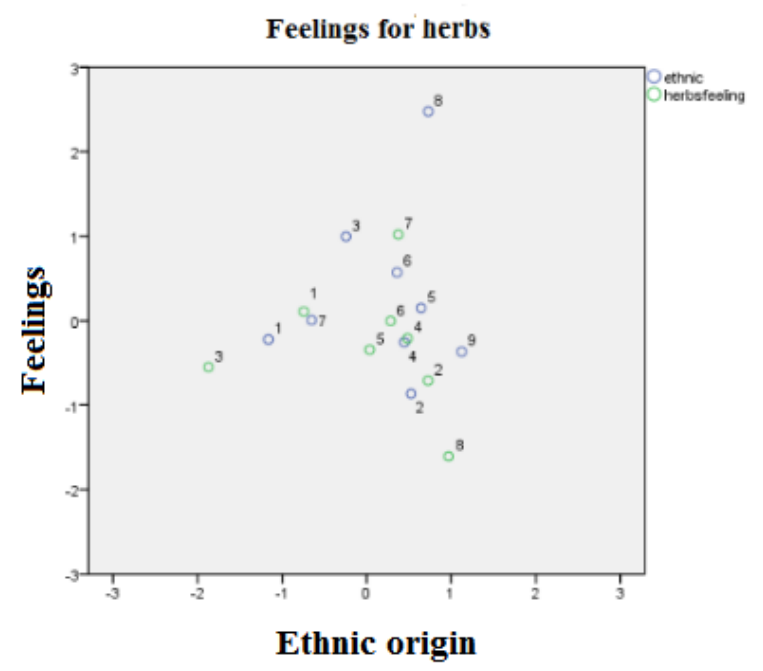

Figure 5: Affective verbal response towards Chinese traditional medicine herbs

The graph above shows that when exposed to the smell of Chinese traditional medicine herbs, ethnic groups South and Central Asian tend to choose 1 (Unpleasant) feelings; South-East Asian, Central and West European tend to experience 2 (Happiness/well-being); West Asian and East European groups tend to choose 7 (Interest), African tend to experience 4 (Energy), while North American tend to experience 6 (Hunger/Thirst). 


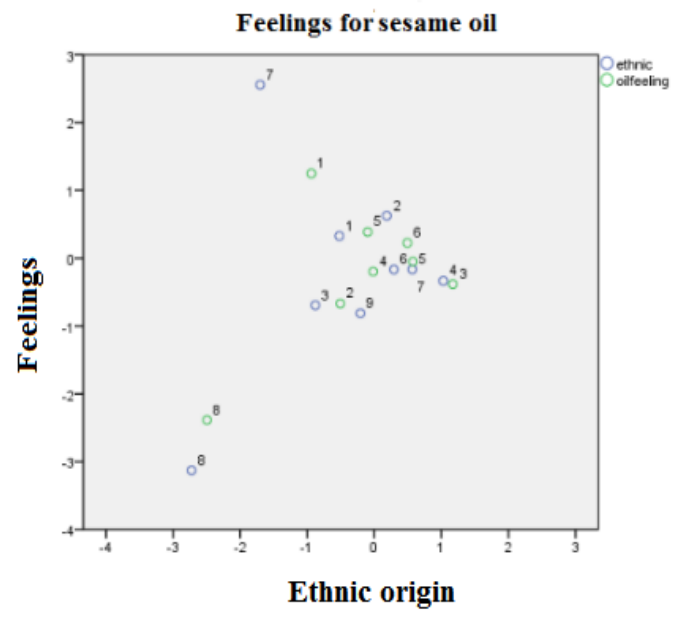

Figure 6: Affective verbal response towards sesame oil

The graph above shows that when exposed to the smell of sesame oil, South and South-East Asian ethnic groups tend to experience 5 (Soothing/Peacefulness); West Asian and West European tend to experience 2 (Happiness/well-being); West Asian tend to experience 4 (Energy); African tend to experience 3 (Sensuality/Desire); North American and East European tend to experience 7 (Interest); Central Asian group has no tendency; Central European tend to experience 8 (Nostalgia).

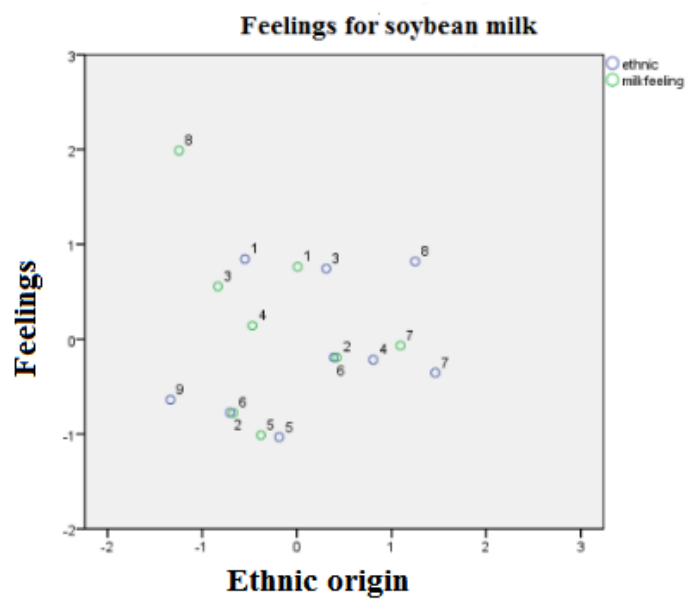

Figure 7: Affective verbal response towards soybean milk

The graph above shows that when exposed to the smell of soybean milk, ethnic groups South Asian tend to experience 3 (Sensuality/Desire); South-East Asian tend to experience 6 (Hunger/Thirst); 3 tend to choose 1 (Unpleasant); African and Central Asian tend to experience 7 (Interest); North American tend to experience 5 (Soothing/Peacefulness); East and West European tend to experience 2 (Happiness/well-being); group Central European has no tendency. 


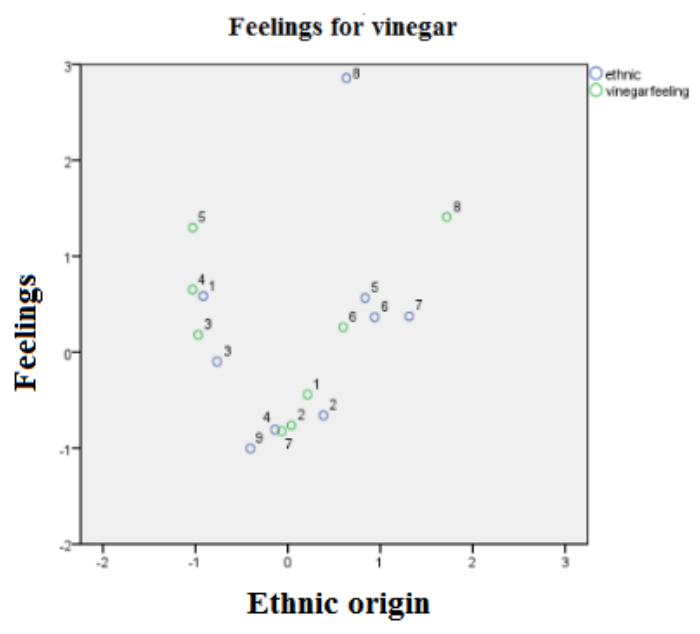

Figure 8: Affective verbal response towards vinegar

The graph above shows that when exposed to the smell of vinegar, ethnic group South Asian tend to experience 4 (Energy); South-East Asian tend to experience 1 (Unpleasant); West Asian tend to experience 3 (Sensuality/Desire); African and West European tend to experience 7 (Interest), North American, East European, and Central Asian ethnic groups tend to experience 6 (Hunger/Thirst); group Central European has no tendency.

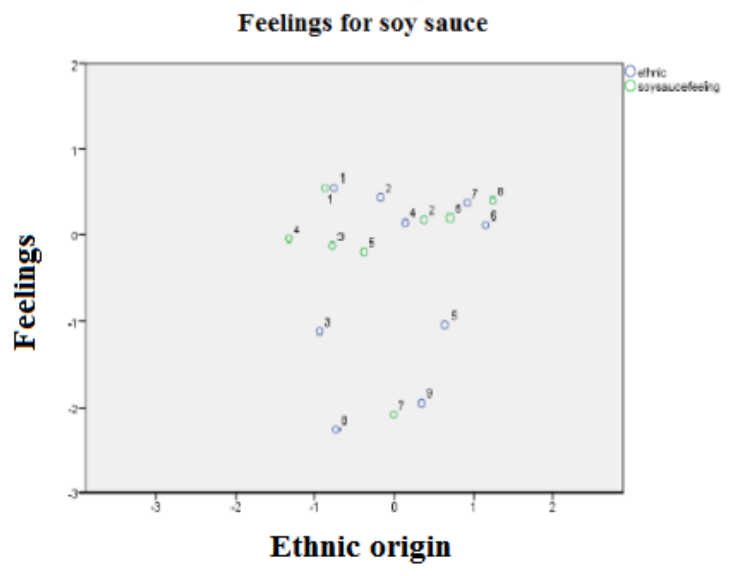

Figure 9: Affective verbal response towards soy sauce

The graph above shows that when exposed to the smell of soy sauce, ethnic group South Asian tend to experience 1 (Unpleasant); South-East Asian and African tend to choose 2 (Happiness/well-being); both West Asian and North American have no tendencies; East European tend to experience 8 (Nostalgia); Central Asian tend to experience 6 (Hunger/Thirst); Central European and West European tend to experience 7 (Interest).

\section{DISCUSSION AND CONCLUSIONS}

The aims of this study were to investigate hedonic perception and affective response to culture-specific odors. Our findings provide important theoretical implications for scent marketing and practical implications for the retailers who wish to expand their business internationally. Current research, to the best of our knowledge, is the first to examine the hedonic perception and affective response of foreigners towards Chinese culture-specific 
odors. Although previous cross-cultural studies by have investigated differences between different countries (Pangborn et al., 1988; Ferdenzi et al., 2013), present study employs diverse sample in terms of different ethnic groups and many kinds of cultural backgrounds to investigate the perception of Chine culture specific odors.

As suggested by previous research, differences on pleasantness evaluations between participants from different regions are largely related to geographic distribution and might be due to traditional food habits and availability of regional flavor sources. For example, southeast Asian region, being regionally closest to China, had the highest ratings of pleasantness and familiarity for Chinese culture-specific odors. Out of all ethnic groups, European, on the other hand, had the most differences with the Asian group both on pleasantness and familiarity. In this study, we were able to find that culture and ethnic origin had a significant impact on odor hedonic perception. We also demonstrated that the further the participant's culture regionally to China the less pleasant and less familiar she finds the odor. Our findings are consistent with a survey conducted by Beijing Institute of Culture Innovation and Communication. It revealed that out of 2407 participants from the US, the UK, France, Australia, Japan and South Korea around $13.3 \%$ felt that they have a very poor understanding of the culture, while more than $60 \%$ said that they have a fair understanding. It was further found that the most recognizable symbol of China is a panda. Although many foreigners do not know much about Chinese culture, the interest is spreading, and over the last years foreigners show increasing interest in China. Possessing a thriving economy and a strong production unit, China is becoming more and more popular destination for foreign entrepreneurs and investors.

Our findings did not provide consistent results to prove the notion that the more pleasant the scent, the more familiar it is. As we can see from the mean scores of pleasantness and familiarity in the table provided below, the more pleasant a particular odor becomes, it does not get more familiar. The reason for this might be that despite being exposed to a particular odor on multiple occasions, it might mean that participants find the odor more bearable but it does not guarantee that they find it more pleasant, as Brand et al. (2012) suggests hedonic perception relies heavily on personal preferences.

Interestingly enough, most of the odors were rated as moderately pleasant, with extreme exceptions of stinky doufu $(\mathrm{M}=2.2)$ and white wine $(\mathrm{M}=3.33)$ as being very unpleasant, and green tea $(M=7.22)$ being very pleasant.

High pleasantness and familiarity evaluations of the green tea may be explained by the fact that it is a famous and popular product with many people all over the world. According to The World Factbook (2015), China is one of the largest global tea exporters with exporting \$1.3 billion dollar value which accounts for $18.2 \%$ of global tea market. Multiple research has proved health benefits of green tea. Cooper et al. (2005) proved its anticancer benefits, Kathy Abascal and Eric Yarnell (2004) noted its antimicrobial benefits, as well as benefits for cardiovascular health as shown by Geleijnse et al. (2002).

The odor of stinky doufu was the second most unpleasant smell after white wine. Some scientists like William Shurtleff and Akiko Aoyagi (2013) claim that doufu was invented in China around 164 BC. But it did not become well-known to many Westerners until mid 20th century. Although many countries use doufu nowadays, stinky doufu is mostly popular in China. Despite being exposed to this odor for a long period of time and having a close association with Chinese culture, participants on average gave stinky doufu low evaluations and expressed negative feelings towards it. Here we argue that although according to the learned view of hedonic perception, we learn to like odors rather than being born programmed 
to like particular odors and dislike the others, it takes considerably longer time to learn to like odors that are considered unpleasant in one's culture.

White wine was one of the odors that received the lowest pleasantness evaluations. In Chinese culture alcohol has been important in sociocultural life. In ancient times, it was an important part of religious or political rituals, harvest celebrations, or simply friends meetings, wedding ceremonies. In Heath (1995) drinking was not only a signal of hospitality but also a sign of respect. In modern China, a popular drink consumed at dinners is baijiu (or white wine). The more the host makes you drunk, the more respect he shows to you, and the more solid relationship is built. The reason for the white wine scoring so low might be that this alcoholic drink is consumed in multiple shots in quick successions, and Westerners simply do not have time to adapt to its unique and unfamiliar flavor. The odors are indeed very different from the odors that participants of this study are used to. Another reason for the low evaluations of pleasantness may be that the drink is consumed in an unfamiliar cultural context which might lead to negative emotions and thus negative associations with the consumed alcohol.

In this research we go beyond stimulus-organism-response (SOR) model, our findings enable us to claim that consumer perception of smell is moderated by past experience and selfassociation with the culture. Our results suggest that odor affective response involves a complex emotional process. These emotions, as stated above, are formed by the amount of interactions with a particular odor and context in which the odor is experienced.

Our findings imply that hedonic perception is not merely organism-stimulus-response, it is a rather complicated process involving moderators. The response is not only affected by the stimulus but more important by the duration of exposure to that stimulus. Our findings show that the more you are exposed to the stimulus the more familiar you find it. We were able to conclude that duration of stay on average affects perception of culture-specific odors. Despite the odors being pleasant or unpleasant, participants who remained in China for a longer period of time on average found odors more familiar. We were not able to find, however, that duration of exposure affect pleasantness. It is more association with the culture that affects the pleasantness. Thus, we demonstrate that, despite the importance of being exposed to a particular smell over an extended period of time to perceive it more pleasant, it is more important to associate yourself with the culture where the smell is particularly common. Thus, duration of stay has a positive effect on the familiarity of scent and not so much on their pleasantness. Association with the culture plays a major role in liking that culture-specific smell.

This research was able to demonstrate that once exposed to a culture-specific odor the organism does not simply respond as argued in SOR model. Hedonic perception towards culture-specific odors is a complicated emotional process, which is moderated by past experience, culture, ethnic origin, duration of stay in China, and self-association with Chinese culture.

\section{MANAGERIAL IMPLICATIONS}

In recent years the popularity of China has increased, more and more foreigners arrive for business, work or study. China's rapid economic growth provides vast opportunities and potential for further development. According to the Annual Report on Chinese International Migration (2015), the number of foreign residents constituted almost 900,000 in 2013. The majority of these foreign residents tend to settle in first-tier cities like Beijing, Shanghai, Guangzhou, etc. In many cases they separate themselves from the rest of the city forming the 
so-called foreign communities. Foreign communities boom in these cities, for example, African community in Guangzhou or Korean in Beijing. Being a considerable fraction on the Chinese market these consumers coming from different cultural backgrounds need a different marketing approach.

This study provides evidence that to enhance consumers' product perception retailers can speculate the product's odor to make the product more pleasant. Association with experience when the consumer was first exposed to an odor can also be employed to create a more pleasant and memorable experience for the consumer. If perceived as unpleasant in one culture, product odor can be changed to the pleasant one. The findings of this study have shown that we learn to like culture-specific odors through close self-association with the culture and multiple exposures to this odors. Thus, Chinese retailers who wish to increase their sales by expanding their business and targeting foreign consumers may employ scents to enhance consumers' experience. It is also necessary to keep in mind that although the first pleasant encounter with a particular odor is important to form a positive association, it is possible to change unpleasant perception into a pleasant one with multiple positive experiences.

\section{LIMITATIONS AND FUTURE RESEARCH}

The first limitation might involve the use of foreigners that live in one Chinese city. One might argue that this creates a bias and does not allow us to generalize our findings. It is necessary to establish the extent to which we can generalize our results across different cities in China. The second limitation concerns the use of only eight odor representing Chinese culture. Although we tried to choose odors familiar to all Chinese, it might be hard to do in a country as big and diverse as China. Given the distinct characteristics of Chinese culture-specific odors, future research should aim at testing more varieties of product scents to investigate hedonic perception. It might also be interesting to compare hedonic perception and affective response of Chinese and foreigners.

\section{References}

Berglund, U. (1974). Dynamic properties of the olfactory system. N.Y.: Acad. Sci., pp. 17-27.

Bloch, P.H., Brunel, F.F. and Arnold, T.J. (2003). Individual differences in the centrality of visual product aesthetics: Concept and measurement. Journal of Consumer Research, 29(4), pp. 551-565

Bone, P.F. and Ellen, P.S. (1999). Scents in the marketplace: explaining a fraction of olfaction. Journal of Retailing, 75(2), pp. 243-62.

Bone, P.F. and Jantrania, S. (1992). Olfaction as a cue for product quality. Marketing Letters, 3(3), pp. $289-296$.

Bone, P.F. and Jantrania, S. (1992). Olfaction as a cue for product quality. Marketing Letters, 3(3), pp. $289-296$.

Bradford, K. D., and Desrochers, D. M. (2010). The Use of Scents to Influence Consumers: The Sense of Using Scents to Make Cents. Journal of Business Ethics, 90(S2), pp. 141-153.

Cain, W.S. (1974). Perception of odor intensity and the time-course of olfactory adaptation. New Heaven: ASHRAE Trans., pp. 53-75.

Carrasco, M., and Ridout, J. B. (1993). Olfactory perception and olfactory imagery: a multidimensional analysis. Journal of Experimental Psychology: Human Perception and Performance, 19(2), pp. 287-301.

Carterette, E. C., and Friedman, M. P., eds. (2013). Handbook of perception: Feeling and Hurting, New York: Academic Press.

Chebat, J.-C. and Michon, R. (2003). Impact of ambient odors on mall shoppers' emotions, cognition, and spending: a test of competitive causal theories. Journal of Business Research, Vol. 56(7), pp. 529-539.

Classen, C., Howes, D., and Synnott, A. (1994). Aroma: The cultural history of smell. New York: Taylor \& Francis. 
Cooper, R., Morré, D. J., and Morré, D. M. (2005). Medicinal benefits of green tea: Part I. Review of noncancer health benefits. Journal of Alternative \& Complementary Medicine, 11(3), pp. 521-528.

Dalton, P. H., Dilks, D. D., and Banton, M. I. (2000). Evaluation of odor and sensory irritation thresholds for methyl isobutyl ketone in humans. AIHAJ-American Industrial Hygiene Association, 61(3), 340-350.

Davies, B.J., Kooijman, D. and Ward, P. (2003). The sweet smell of success: olfaction in retailing. Journal of Marketing Management, 19(5-6), pp. 611-627.

Doucé, L., Poels, K., Janssens, W., and De Backer, C. (2013). Smelling the books: the effect of chocolate scent on purchase-related behavior in a bookstore. Journal of Environmental Psychology, 36, pp. 65-69.

Ellen, P. S. (1994). Olfaction and Marketing: Does it Make Sense to Use Scents? unpublished working paper, Department of Marketing, West Virginia University

Ellen, P.S. and Bone, P.F. (1998). Does it matter if it smells? Olfactory stimuli as advertising. Executional cues. Journal of Advertising, 27(4), pp. 29-39

Engen, T., and Corbit, T. E. (1970). Feasibility of Olfactory Coding of Nozious Substances to Assure Aversive Responses in Young Children. Final Report.

Engen, T., and Engen, E. A. (1997). Relationship between development of odor perception and language. Enfance, (1), pp. 125-140.

Ferdenzi, C., Roberts, S. C., Schirmer, A., Delplanque, S., Cekic, S., Porcherot, C., and Grandjean, D. (2013). Variability of affective responses to odors: culture, gender, and olfactory knowledge. Chemical senses, 38(2), pp. 175-186.

Geleijnse, J. M., Launer, L. J., van der Kuip, D. A., Hofman, A., and Witteman, J. C. (2002). Inverse association of tea and flavonoid intakes with incident myocardial infarction: the Rotterdam Study. The American journal of clinical nutrition, 75(5), pp. 880-886.

Gulas, C. S., \& Bloch, P. H. (1995). Right under our noses: Ambient scent and consumer responses. Journal of Business and Psychology, 10(1), pp. 87-98.

Heath, D.B. (1995). International handbook on alcohol and culture. United States: Greenwood Press

Hermann, A., Zidanek, M., Sprott, D. E., and Spangenberg, E. R. (2013). The power of simplicity: Processing fluency and the effects of olfactory cues on retail sales. Journal of Retailing, 89, pp. 30-43

Herz, R.S., and Cupchik, G.C. (1995). The emotional distinctiveness of odor-evoked memories in humans. Chemical Senses, 20, pp. 517-528.

Herz, R.S., and Engen, T. (1996). Odor memory: Review and analysis. Psychonomic Bulletin \& Review, 3, pp. 300313.

Herz, R. S. (1998). Are odors the best cues to memory?: A cross-modal comparison of associative memory stimuli. Annals of the New York Academy of Sciences, 855, pp. 670-674.

Herz, R. S., Eliassen, J., Beland, S., and Souza, T. (2004). Neuroimaging evidence for the emotional potency of odorevoked memory. Neuropsychologia, 42(3), pp. 371-378.

Hirsch, A.R. (1995). Effects of Ambient Odors on Slot Machine Usage in a Las Vegas Casino. Psychology \& Marketing, 12 (7), pp. 585-94.

Hirschmann, E. and Holbrook, M. (1982) Hedonic consumption. Journal of Marketing, 46 (2), pp 92-101

Holland, R. W., Hendriks, M., and Aarts, H. (2005). Smells like clean spirit: Nonconscious effects of scent on cognition and behavior. Psychological Science, 16(9), pp. 689-693.

Hulten, B. (2011). Sensory marketing: The multi-sensory brand-experience concept. European Business Review, 23, pp. 256-273.

Krishna, A., Lwin, M. O., and Morrin, M. (2010). Product scent and memory. Journal of Consumer Research, 37, pp. 57-67 
Krishna, A. (ed.) 2010 Sensory Marketing: Research on the Sensuality of Products, Taylor \& Francis Group LLC, New York

Krishna, A., ed. (2010) Sensory marketing: Research on the sensuality of products. New York: Routledge Academic.

Kotler, P. (1974). Atmospherics as a marketing tool. Journal of Retailing, 49, pp. 48-64.

Laird, D.A. (1935). What can you do with your nose? Scientific Monthly, 41, pp. 126-130.

Lindstrom, M. (2005). Broad sensory branding. Journal of Product \& Brand Management, 14(2), pp. 84-87

Mandairon, N., Poncelet, J., Bensafi, M., and Didier, A. (2009). Humans and mice express similar olfactory preferences. PLoS ONE, 4(1), p. e4209.

Mattila, A.S. and Wirtz, J. (2001). Congruency of scent and music as a driver of in-store evaluations and behavior. Journal of Retailing, 77(2), pp. 273-289

Mehrabian, A., and Russell, J. A. (1974). An approach to environmental psychology. Cambridge, MA: MIT Press.

Mitchell, D. J. (1994). For the smell of it all: functions and effects of olfaction in consumer behavior. Advances in Consumer Research, 21(1), p. 330.

Mitchell, D. J., Kahn, B. E., and Knasko, S. C. (1995). There's something in the air: Effects of congruent or incongruent ambient odor on consumer decision making. Journal of Consumer Research, 22(2), pp. 229-238.

Morrin, M. and Ratneshwar, S. (2000). The impact of ambient scent on evaluation, attention, and memory for familiar and unfamiliar brands. Journal of Business Research, 49(2), pp. 157-65.

Moskowitz, H. R., Dravnieks, A., and Klarman, L. A. (1976). Odor intensity and pleasantness for a diverse set of odorants. Perception \& Psychophysics, 19(2), pp. 122-128.

Pangborn, R. M., Guinard, J. X., and Davis, R. G. (1988). Regional aroma preferences. Food Quality and Preference, 1(1), pp. 11-19.

Plailly, J., Delon-Martin, C., and Royet, J. P. (2012). Experience induces functional reorganization in brain regions involved in odor imagery in perfumers. Human brain mapping, 33(1), pp. 224-234.

Proust, M. and Davis, L. (2003) In search of lost time: The way by Swann's: The way by Swann's Vol 1 (in search of lost time 1). Edited by Christopher Prendergast. London: Penguin Classics.

Richardson, J. T., and Zucco, G. M. (1989). Cognition and olfaction: a review. Psychological bulletin, 105(3), p. 352.

Robin, O., Alaoui-Ismaili, O., Dittmar, A., and Vernet-Maury, E. (1999). Basic emotions evoked by eugenol odor differ according to the dental experience. A neurovegetative analysis. Chemical senses, 24(3), pp. 327-335.

Rozin, P., \& Millman, L. (1987). Family environment, not heredity, accounts for family resemblances in food preferences and attitudes: a twin study. Appetite, 8(2), pp. 125-134.

Russell, J. A., and Pratt, G. (1980). A description of the affective quality attributed to environments. Journal of Personality and Social Psychology, 38(2), pp. 311-322.

Schifferstein, H.N.J. and Blok, S.T. (2002). The signal function of thematically (in) congruent ambient scents in a retail environment. Chemical Senses, 27(6), pp. 539-49.

Schifferstein, H. N. J., and Michaut, A. M. K. (2002). Effects of appropriate and inappropriate odors on product evaluations. Perceptual and Motor Skills, 95(1), pp. 199-1214.

Schleidt, M., Hold, B., and Attila, G. (1981). A cross-cultural study on the attitude towards personal odors. Journal of Chemical Ecology, 7, pp. 19-31.

Shepherd, G. M. (2004). The human sense of smell: are we better than we think? PLoS Biol, 2(5), p. e146.

Shurtleff, W., and Aoyagi, A. (2013). History of Tofu and Tofu Products (965 CE to 2013). USA: Soyinfo Center.

Spangenberg, E.R., Crowley, A.E. and Henderson, P.W. (1996). Improving the store environment: do olfactory cues affect evaluations and behaviors? Journal of Marketing, 60(2), pp. 67-80. 
Spangenberg, E.R, Sprott, D.E, Grohmann B., Tracy D.L. (2004). Effects of gender congruent ambient scent on approach and avoidance behaviors in a retail store. Unpublished manuscript.

Spangenberg, E.R., Sprott, D.E., Grohmann, B. and Tracy, D.L. (2006). Gender-congruent ambient scent influences on approach and avoidance behaviors in a retail store. Journal of Business Research, 59(12), pp. 1281-1287.

Spence, C. (2012). Managing sensory expectations concerning products and brands: Capitalizing on the potential of sound and shape symbolism. Journal of Consumer Psychology, 22, pp. 37-54.

Sulmont, C., Issanchou, S., and Köster, E. P. (2002). Selection of odorants for memory tests on the basis of familiarity, perceived complexity, pleasantness, similarity and identification. Chemical Senses, 27(4), pp. 307-317.

Ward, P., Davies, B.J. and Kooijman, D. (2003). Ambient smell and the retail environment: relating olfaction research to consumer behavior. Journal of Business and Management, 9(3), pp. 289-302.

Warm, J. S., Dember, W. N., and Parasuraman, R. (1991). Effects of olfactory stimulation on performance and stress in a visual sustained attention task. Journal of Social Cosmetic Chemistry, 42, pp. 199-210.

Zufall, F., and Leinders-Zufall, T. (2000). The cellular and molecular basis of odor adaptation. Chemical senses, 25(4), pp. 473-481. 